\title{
Addressing the effects of transcultural nursing education on nursing students' cultural competence: A systematic review
}

\author{
Betiil Tosun ${ }^{\text {h,1,2,* }}$, BENEFITS Group

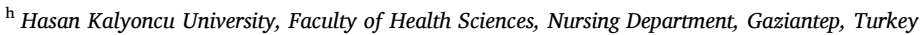

\section{A R T I C L E I N F O}

\section{Keywords:}

Transcultural nursing

Education

Curriculum

Course

Effectiveness

Cultural competence

Knowledge

Skills

Attitude

Nursing students

\begin{abstract}
A B S T R A C T
Aim: This study aimed to synthesize the findings of studies evaluating educational programs providing curricular transcultural nursing education.

Backgrounds: Nursing care education about cultural diversity and experience with taking care of patients from different cultures and special populations are significant factors that could likely influence cultural competence. The effect of transcultural nursing education given to nursing students has been investigated by different researchers and different methods. Addressing the effects of transcultural nursing education on nursing students' cultural awareness, knowledge and attitudes can contribute to future transcultural nursing education activities and the creation of training content.

Design: This study was a methodological systematic review study.

Methods: Methodological quality was assessed following the PRISMA guidelines. PubMed, Science Direct, APA PsycArticles, OVID, EBSCO, and Web of Science databases were searched from 2010 to 2020. The following keywords were used: "Transcultural nursing", "education", "curriculum", "course", "effectiveness", "cultural competence", "knowledge", "skills", "attitudes", and "nursing students". Studies published in peer-reviewed journals in English using both experimental and quasi-experimental designs were included.

Results: Total of 11 research papers, $(n=1375)$ nursing students' outputs were included in this review. Cultural competence interventions/programs were provided as part of the core theoretical courses or as elective courses. Different durations and types of teaching methods included debates, discussions, case scenarios, practicums, simulation, international learning projects, experiential learning, storytelling, and traditional teaching lectures. In ten studies, an increase in the level of culture-related competences was reported as statistically significant (p $<0.05)$.

Conclusions: Limited studies have generally proven the effectiveness of transcultural nursing education provided to nursing students. Education content, training methods and training periods were not standard in the literature. More comprehensive, valid and reliable measurement tools are needed to evaluate the education provided for nursing students.
\end{abstract}

\section{Introduction}

Nursing is grounded on a humanistic and holistic approach that harmonizes compassion, honesty, kindness, altruism in delivery of healthcare and involves taking into account the cultural needs of patients, need for equal access to health care, respect for cultural background, beliefs and safety needs (Papadopoulos et al., 2021; Prosen, 2015). Transcultural nursing education is closely linked to the belief that nursing should provide individualized, high-quality, appropriate care to all individuals (McFarland and Wehbe-Alamah, 2019).

Nurses must have sufficient knowledge about different cultural backgrounds and traditions to be competent to perform holistic patient assessments (Albougami et al., 2016). Therefore, nursing students must develop cultural awareness, knowledge, and skills through a transcultural nursing curriculum before graduation (Byrne, 2020). Campinha-Bacote's model explains cultural competence as a process that nurses must undertake to develop the capacity to provide efficient and high-quality care, encompassing five components (Albougami et al.,

\footnotetext{
* Corresponding author.

E-mail address: tosunbetul@gmail.com.

1 Postal Address: Hasan Kalyoncu University 8th Km on the Airport Road, Sahinbey / GAZIANTEP

2 ORCID: https://orcid.org/0000-0002-4505-5887
} 
2016; Campinha-Bacote, 2011). Cultural awareness is a process by which healthcare professionals consciously acknowledge their own cultural background and help them avoid prejudices against other cultures. Cultural skills are defined as the ability to obtain necessary information from patients through culturally appropriate behavior and physical assessment. Cultural knowledge is another component by which health professionals open their minds to see diversities in cultural characteristics regarding illness and patient beliefs towards health. Cultural encounter explain the interaction between healthcare professionals and members of different cultures. The final component is cultural desire, which is the force of being educated, talented, competent and culturally conscious (Campinha-Bacote, 2011; O'Brien et al., 2021; Prosen, 2015; Repo et al., 2017). Nursing students should be aware of their own cultural values, beliefs, attitudes, and behaviors and possess the appropriate assessment and communication skills to interact with individuals from different cultural backgrounds (Sarafis and Malliarou, 2013). However, for the most part, the nursing educational system does not consider cultural competence as a main attitude in general (Ke and Hsu, 2015; Raigal-Aran et al., 2017). As a result, nursing students can feel inadequately prepared to provide culturally competent care to populations with different cultural backgrounds (Von Ah and Cassara, 2013). Some studies have found that nursing students named barriers, such as exhibiting a lack of confidence and transcultural self-efficacy and having problems with different languages, while assessing patients from different cultural backgrounds (Sarafis and Malliarou, 2013; Karatay et al., 2016). Given these factors, the most important facilitators of the development of cultural competence were cultural encounters, knowledge, and experiences (Chen et al., 2018; Choi and Kim, 2018). It was found that nursing care education about cultural diversity and experience with taking care of patients from different cultures and special populations were significant factors that could likely influence cultural competence (Cruz et al., 2016, 2017).

In nursing education, cultural awareness is one of the most important components of culturally competent nursing care. Cultural awareness can also be an indispensable component of understanding one's own cultural characteristics and values, which helps in understanding the cultural beliefs, values and behaviors of others (Kaihlanen et al., 2019). Cultural awareness of one's own beliefs, values, attitudes and practices has been defined as an essential first step before cultural knowledge (Brooks et al., 2019). Therefore, nursing education should include cultural values, behaviors, diversities and norms that will support students' cultural awareness (Hultsjö et al., 2019). It should also be involved in the development of interpersonal relationships to gain cultural awareness skills (Quickfall, 2014). Liang et al. (2019) emphasized that cultural competence education should be integrated into nursing courses to improve nursing students' perceptions and skills regarding cultural care competence. Similarly, Halabi and de Beer (2018) revealed that half of the students preferred to receive transcultural nursing education related to working with people from different cultures. Therefore, identifying which topics should be covered by transcultural nursing education is very important in training culturally competent nursing students. Additionally, addressing the effects of transcultural nursing education on nursing students' cultural awareness, knowledge and attitudes can contribute to future transcultural nursing education activities and the creation of training content.

This study aimed to synthesize the findings of studies evaluating educational programs providing transcultural nursing education in the curricula.

\section{Methods}

This study was conducted as a systematic literature review. The authors followed the Preferred Reporting Items for Systematic Reviews and Meta-Analyses (PRISMA) recommendations and the Centre for Review and Dissemination (CRD) (CRD, 2009; Moher et al., 2009; Tufanaru et al., 2017).

\subsection{Literature search strategy}

First, three researchers from the study group (VT, VO, SF) examined the PubMed, Science Direct, APA PsycArticles ${ }^{\circledR}$, OVID, EBSCO, and Web of Science databases using the same keywords on the same date. Given the rapid increase in nursing research about transcultural nursing education, the search strategy was limited to articles published between 2010 and 2020 using Boolean combinations of the following keywords: "Transcultural Nursing", "Education", "Curriculum", "Course", "Effectiveness", "Cultural competence", "Knowledge", "Skills", "Attitude", and "Nursing Students" (Table 1).

To conduct a detailed search, the authors also explored keywords including relevant Medical Subject Headings (MeSH) terms, such as Transcultural Nursing, Education, Curriculum, Cultural Competence, Knowledge, Attitude, and Nursing Students.

\subsection{Study selection}

According to PRISMA recommendations (Moher et al., 2009), research studies were identified using database searches and manual searches via review studies' reference lists (Vassar et al., 2016). Duplicated records were deleted, and the remaining records were alphabetically listed by the first author's surname. The final list of 20 articles was shared with all "Better \& Effective Nursing Education For Improving Transcultural Nursing Skills (BENEFITS)" project team members for eligibility assessment, including clear instructions for the inclusion/exclusion criteria. BENEFITS project team members agreed to exclude nine articles. The final list of 11 articles included eligible material to complete this review.

\subsection{Inclusion/exclusion criteria}

Only studies published in peer-reviewed journals in English were included in this systematic review. To be included, studies had to focus on interventions to improve transcultural nursing undergraduate education. In terms of design, only randomized control studies or quasiexperimental studies were included (Table 2).

\subsection{Eligibility criteria}

The review was completed first by the titles of the studies, then by abstracts, and finally by full texts by a pair of reviewers. In case of doubt regarding eligibility, the article was included. A minimum level of agreement between reviewers was set at $95 \%$. In case of disagreement, the principal investigators (BT and AY) contacted the reviewers to resolve the differences. Papers were then sent to the same reviewers to double check the abstracts. Finally, specifying the exclusion rationale, a preliminary list identifying the selected records was obtained (Fig. 1).

Table 1

Example of the first search strategy in Web of Science.

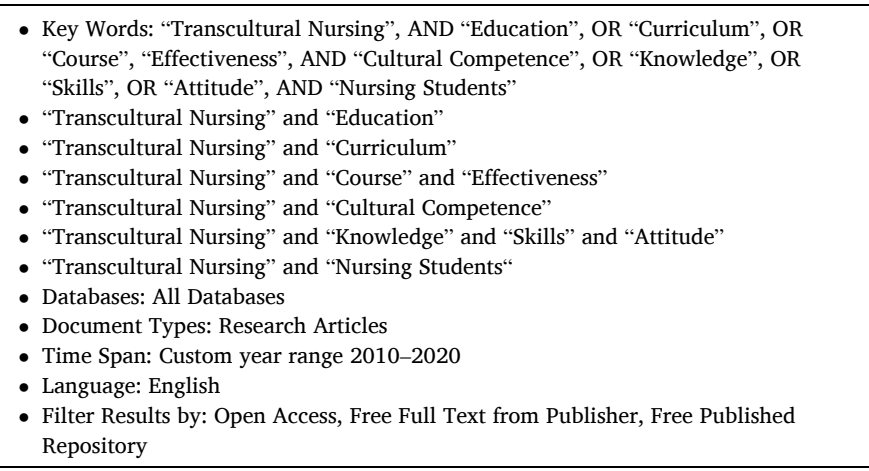


Table 2

Inclusion and exclusion criteria using the PICOS format.

\begin{tabular}{|c|c|c|}
\hline Criteria & Inclusion criteria & Exclusion criteria \\
\hline Population & Nursing students & $\begin{array}{l}\text { Samples consisting of students of other healthcare } \\
\text { professions }\end{array}$ \\
\hline Interventions & Education, curriculum interventions, course, short-term intensive education & Non-educational interventions \\
\hline Comparators & Standard practice, alternative interventions, new method course, new curriculum education & $\begin{array}{l}\text { Evaluating the impact of a lecture in a course or a } \\
\text { presentation at a scientific event }\end{array}$ \\
\hline Outcomes & $\begin{array}{l}\text { Addressing nursing students' outcomes (e.g., overall or subdomain of cultural competence, } \\
\text { confidence of transcultural nursing skills competence) or nursing students' experiences on } \\
\text { patients' care }\end{array}$ & $\begin{array}{l}\text { Not relevant to the cultural competence, confidence } \\
\text { of transcultural nursing skills competence }\end{array}$ \\
\hline $\begin{array}{l}\text { Study design and } \\
\text { publication type }\end{array}$ & $\begin{array}{l}\text { Randomized controlled trials, non-randomized controlled trials, quasi-experimental studies, } \\
\text { before and after comparison studies, mixed methods }\end{array}$ & $\begin{array}{l}\text { Only descriptive studies, qualitative studies, case } \\
\text { reports, reviews or meta-analyses }\end{array}$ \\
\hline Publication years & $2010-2020$ & Other years (prior to 2010) \\
\hline Language & English & Other languages \\
\hline
\end{tabular}

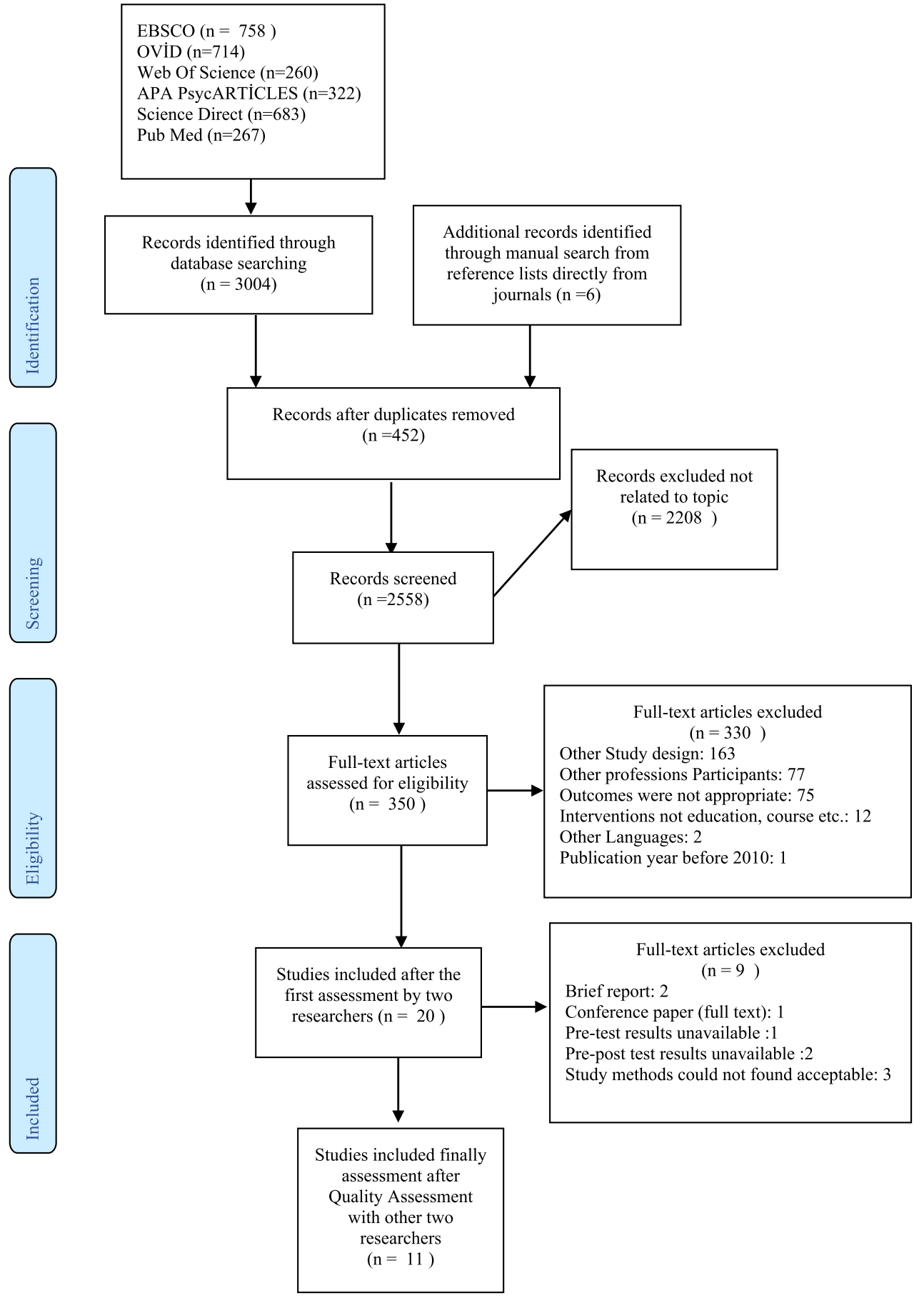

Fig. 1. Study follow diagram. 


\subsection{Data extraction}

A matrix was created to collect relevant data from individual papers, and it was sent to reviewers to complete. The responsible researchers verified the extracted data and subsequent analysis and resolved all inconsistencies.

\subsection{Assessment of study quality and risk of bias}

Two researchers (AY, BT) independently assessed the methodological quality of each study (Tufanaru et al., 2017). All disagreements concerning the quality of the studies were discussed, double checked, and decided upon by the principal investigators. Studies were included in the systematic review if a score of at least fifty percent was awarded to the critical appraisal, which was the predetermined cut-off point agreed upon by the research team (Popay et al., 2006; Porritt et al., 2014). Given the design of the articles included in this review and the details provided, the risk of bias assessment was not possible.

\section{Results}

This section will present the results of the analysis conducted to examine the eleven papers selected for this review.

\subsection{Study selection}

A total of 3010 articles were initially identified for screening by the research team. Then, 452 of them were excluded due to duplication. The titles and abstracts of 2558 documents were screened, and a total of 2208 articles were excluded from the review as a result of not fully complying with the inclusion criteria. After inspection of the full texts of
350 articles, 330 were considered irrelevant for the purpose of this research. At this point, many papers were discarded due to not complying entirely with the inclusion criteria. A total of twenty articles were selected, although discrepancies were observed within the team. After the resolution of conflicts, a final sample of eleven manuscripts was selected by consensus for this systematic review. Those retained were examined further (Fig. 1).

\subsection{Methodological quality}

Of the eleven studies selected for this review, six used a quasiexperimental design (Amerson, 2010; Jeffreys and Dogan, 2012; Grossman et al., 2012; Allen et al., 2013; Noble et al., 2014; Halter et al., 2015), and four used a mixed-methods approach (Richards and Doorenbos (2016)). Wolfe Kohlbry (2016); Muir-Cochrane et al. (2018), Liang et al. (2019)). Only one (Ozkara San, 2018) used a longitudinal design. No randomized controlled trials were identified in this search.

In all selected studies, there was a marked risk of selection bias due to the lack of a randomized selection procedure before assignment to intervention groups. Equally, no description regarding, for instance, blind group allocation (when applicable) was reported. All studies described data analysis procedures, and significance testing was reported. However, the study protocols were not always available for examination, which prevented further comparison.

\subsection{Description of selected studies}

Tables 3 and 4. provides an overview of the chosen articles for this review. The studies were conducted between 2010 and 2018 mainly in four countries: the United States (Amerson, 2010; Jeffreys and Dogan, 2012; Grossman et al., 2012; Halter et al., 2015; Richards and

Table 3

Selected studies' methodologies.

\begin{tabular}{|c|c|c|c|}
\hline $\begin{array}{l}\text { Author, year and } \\
\text { country }\end{array}$ & Participants & $\begin{array}{l}\text { Type of } \\
\text { intervention }\end{array}$ & Follow up instruments \\
\hline $\begin{array}{l}\text { Allen et al. (2013) } \\
\text { Australia }\end{array}$ & $\begin{array}{l}\text { Baccalaureate nursing students } \\
\mathrm{n}=251\left(\mathrm{n}_{\text {pretest }}=33 ; \mathrm{n}_{\text {posttest }}=33\right)\end{array}$ & $\begin{array}{l}\text { Quasi- } \\
\text { experimental } \\
\text { study }\end{array}$ & $\begin{array}{l}\text { Transcultural Self-Efficacy Tool (TSET) } \\
\text { Quick Discrimination Index (QDI) }\end{array}$ \\
\hline $\begin{array}{l}\text { Amerson (2010) } \\
\text { USA }\end{array}$ & $\begin{array}{l}\text { Baccalaureate nursing students } \\
\mathrm{n}=69\left(\mathrm{n}_{\text {pretest }}=60 ; \mathrm{n}_{\text {posttest }}=60\right)\end{array}$ & $\begin{array}{l}\text { Quasi- } \\
\text { experimental } \\
\text { study }\end{array}$ & TSET \\
\hline $\begin{array}{l}\text { Grossman et al. } \\
\text { (2012) } \\
\text { USA \& Norway }\end{array}$ & $\begin{array}{l}\text { Nursing students in an American senior class }(n=48) \text { and } \\
\text { Norwegian seniors }(n=25)\end{array}$ & $\begin{array}{l}\text { Quasi- } \\
\text { experimental } \\
\text { study }\end{array}$ & TSET \\
\hline $\begin{array}{l}\text { Halter et al. (2015) } \\
\text { USA }\end{array}$ & Baccalaureate nursing students $(n=260)$ & $\begin{array}{l}\text { Quasi- } \\
\text { experimental } \\
\text { study }\end{array}$ & TSET \\
\hline $\begin{array}{l}\text { Jeffreys and Dogan } \\
\text { (2012) }\end{array}$ & Associate degree nursing students & $\begin{array}{l}\text { Quasi- } \\
\text { experimental }\end{array}$ & TSET \\
\hline USA & $\begin{array}{l}\text { - cross-sectional }(\mathrm{n}=147) \\
\text { - longitudinal }(\mathrm{n}=36)\end{array}$ & study & \\
\hline $\begin{array}{l}\text { Liang et al. (2019) } \\
\text { Taiwan }\end{array}$ & Nursing students $n=48$ & $\begin{array}{l}\text { Mixed-methods } \\
\text { study }\end{array}$ & $\begin{array}{l}\text { Self-perceived cultural care competence (SP-CCC) questionnaire } \\
(\mathrm{n}=48) \text { And focus group interviews }(\mathrm{n}=10)\end{array}$ \\
\hline $\begin{array}{l}\text { Muir-Cochrane et al. } \\
\text { (2018) } \\
\text { Australia }\end{array}$ & Nursing students $n=43$ (undergraduate and postgraduate) & $\begin{array}{l}\text { Mixed-methods } \\
\text { study }\end{array}$ & $\begin{array}{l}\text { The Kiersma-Chen Empathy Scale } \\
\text { Mental Health Nursing Clinical Confidence Scale, } \\
\text { The Cultural Competence Questionnaire (theory of planned } \\
\text { behavior-(TPB)-CCQ). } \\
\text { focus group and interviews }(\mathrm{n}=21)\end{array}$ \\
\hline $\begin{array}{l}\text { Noble et al. (2014) } \\
\text { Israel }\end{array}$ & $\begin{array}{l}\text { First-year nursing students } n=146 \\
\text { intervention group }(n=58) \text { and control group }(n=88)\end{array}$ & $\begin{array}{l}\text { Quasi- } \\
\text { experimental } \\
\text { study }\end{array}$ & $\begin{array}{l}\text { Campinha-Bacote's Inventory for Assessing the Process of Cultural } \\
\text { Competence Among Healthcare Professional-Revised IAPCC-R }\end{array}$ \\
\hline $\begin{array}{l}\text { Ozkara San (2018) } \\
\text { USA }\end{array}$ & $\begin{array}{l}\text { Nursing students } \\
N=53(\text { n pretest }=53)(n \text { posttest }=53)\end{array}$ & Longitudinal study & TSET \\
\hline $\begin{array}{l}\text { Richards and } \\
\text { Doorenbos (2016) } \\
\text { USA }\end{array}$ & $\begin{array}{l}\text { Various students of health education programs (nursing, } \\
\text { medicine, health-related disciplines, pharmacy, rehabilitation } \\
\text { science) } \\
\text { Total: } 18\left(\mathrm{n}_{\text {pretest }}=18\right)\left(\mathrm{n}_{\text {posttest }}=18\right)\end{array}$ & $\begin{array}{l}\text { Mixed-methods } \\
\text { study }\end{array}$ & $\begin{array}{l}\text { The Intercultural Effectiveness Scale (IES) } \\
\text { The Intercultural Sensitivity Scale (ISS) }\end{array}$ \\
\hline $\begin{array}{l}\text { Wolfe Kohlbry (2016) } \\
\text { USA }\end{array}$ & $\begin{array}{l}\text { Baccalaureate nursing students } \\
\mathrm{n}=121 \\
\left(\mathbf{n}_{\text {pretrip }}=161 ; \mathbf{n}_{\text {posttrip }}=121\right)\end{array}$ & $\begin{array}{l}\text { Mixed-methods } \\
\text { study }\end{array}$ & $\begin{array}{l}\text { Inventory for Assessing the Process of Cultural Competence } \\
\text { Among Healthcare Professionals-Student Version (IAPCC-SV) } \\
\text { Cultural Self-Efficacy Scale (CSES) }\end{array}$ \\
\hline
\end{tabular}


Table 4

Educational content of the review studies about cultural nursing skills interventions.

\begin{tabular}{|c|c|c|c|c|c|}
\hline Studies Author (year) & Cultural awareness & Cultural knowledge & Cultural skill & Cultural encounter & Cultural desire \\
\hline Allen et al. (2013) & $\mathrm{X}$ & $\mathrm{X}$ & $\mathrm{X}$ & $\mathrm{X}$ & - \\
\hline Amerson (2010) & $\mathrm{X}$ & $\mathrm{X}$ & $\mathrm{X}$ & - & - \\
\hline Grossman et al. (2012) & $\mathrm{X}$ & - & $\mathrm{X}$ & - & - \\
\hline Halter et al. (2015) & $\mathrm{X}$ & - & $\mathrm{X}$ & - & - \\
\hline Jeffreys and Dogan (2012) & $\mathrm{X}$ & - & $\mathrm{X}$ & - & - \\
\hline \multicolumn{6}{|l|}{ Liang et al. (2019) } \\
\hline Muir-Cochrane et al. (2018) & - & - & - & - & - \\
\hline Noble et al. (2014) & $\mathrm{X}$ & $\mathrm{X}$ & $\mathrm{X}$ & $\mathrm{X}$ & $\mathrm{X}$ \\
\hline Ozkara San (2018) & $\mathrm{X}$ & $\mathrm{X}$ & $\mathrm{X}$ & $\mathrm{X}$ & $\mathrm{X}$ \\
\hline Richards and Doorenbos (2016) & $\mathrm{X}$ & $\mathrm{X}$ & $\mathrm{X}$ & $\mathrm{X}$ & $\mathrm{X}$ \\
\hline Wolfe Kohlbry P., (2016) & $\mathrm{X}$ & $\mathrm{X}$ & $\mathrm{X}$ & $\mathrm{X}$ & $\mathrm{X}$ \\
\hline
\end{tabular}

Doorenbos, 2016; Wolfe Kohlbry, 2016; Ozkara San, 2018), Australia (Allen et al., 2013; Muir-Cochrane et al., 2018), Israel (Noble et al., 2014), and Taiwan (Liang et al., 2019). Nevertheless, several of them focused on international experiences abroad (Amerson, 2010; Grossman et al., 2012; Richards and Dorenboos, 2016; Wolfe Kohlbry, 2016).

All interventions were conducted in the academic setting, although two of them also included hospital settings (Liang et al., 2019) and international local community experiences (Amerson, 2010). In all cases, participants were bachelor's-level undergraduate students, except for Muir-Cochrane et al. (2018), who also included postgraduate students. In total, 1305 students were considered in this review.

\subsection{The cultural competence interventions}

The proposed programs varied significantly in length (one day to one semester) and, correspondingly, total hours included in the diverse curricula.

The theoretical background of the manuscripts was clearly explained in all cases, except for one article (Grossman et al., 2012). Four studies used Jeffrey's "Cultural Competence and Confidence Model" as a guiding theoretical context (Amerson, 2010; Ozkara San, 2018; Jeffreys and Dogan, 2012, Halter et al., 2015). Wolfe Kohlbry (2016) focused on the "Campinha-Bacote's Model" and "The Process of Cultural Competence in the Delivery of Healthcare Services". Richards and Doorenbos (2016) used "Benett's Developmental Model of Intercultural Sensitivity (DMIS)" as well as "Deardorff's Process Model of Intercultural Competence (PMIC)" guide their research. Two studies chose to combine a "Social Constructivist Model of Health" with the "Theory of Transcultural Nursing" (Allen et al., 2013) or used the "Interpretative Pedagogy Theory", which mentions the "Theory of Planned Behavior" (Muir-Cochrane, 2018).

Noble et al. (2014) used "Campinha-Bacote's Model of Cultural Competence" in their quasi-experimental study. Most recently, the mixed-methods study by Liang et al. (2019) used two transcultural nursing seminal models in the design: the "Sunrise Model" (Leininger and McFarland) and "Campinha-Bacote's Process Model" on cultural competence.

A variety of teaching methods are described in the obtained manuscripts, including simulations (Grossman et al., 2012), standardized patient simulation (Ozkara San, 2018), and clinical simulation (Richards and Doorenbos, 2016).

More traditional instruction methods were proposed by Noble et al. (2014), who combined an introduction to the nursing course with lectures, discussion and students' presentations on the topic. Halter et al. (2015) were similarly conservative in their teaching approaches and interventions, including lectures with participation, reflective papers, cultural competence readings and journal clubs. Allen et al. (2013) used class debates and case scenarios to raise students' cultural competence. Tutorials and lectures were combined with practicums in their labs. A slightly more innovative program was observed in the study by Amerson et al. (2010), which used service-learning projects with not only local but also international communities to facilitate cultural immersion. Wolfe Kohlbry (2016) also used experiential learning through immersive international experiences in diverse communities. The triangulated methodology of this intervention examined changes in the components and level of cultural competence of their BSc students. A more comprehensive approach was taken in the recent study by Liang et al. (2019), which was based on the didactic teaching of the "Sunrise Model" combining interactive learning, such as role playing or specific scenarios, with reflective feedback across the program (Table 5).

\subsection{The duration of the intervention programs}

As highlighted earlier, great variability was observed in terms of the length of the proposed interventions to estimate changes in cultural competence. For instance, Allen et al. (2013) reported $72 \mathrm{~h}(\mathrm{~h})$ in total activities distributed across an 8-week program comprising theatrical presentation teaching ( $1 \mathrm{~h}$ per week), tutorials ( $2 \mathrm{~h}$ per week) and labs ( $1 \mathrm{~h}$ per week). Although only a community health program was described, Amerson (2010) did not state the total duration of the program. Grossman et al.'s (2012) pilot study used two simulation scenarios per semester followed by 20-minute debriefing sessions with instructors. Jeffreys and Dogan (2012) provided a thorough description of the clinical nursing curriculum course of 30-week medical and surgical courses and four 7.5-week courses, including clinical rotations elapsed in between measures. Halter et al.'s (2015) three-year study emphasized student opportunities to participate in cultural interventions, conferences, international symposia and real-life scenarios as examples. Although examples of teaching learning interventions were provided in Halter et al.'s (2015) study for year one, the whole program and/or timing were not provided clearly. Ozkara San (2018) is one of the few examples where the educational intervention was clearly described in the paper. The simulation scenarios were embedded in a 15-week nursing course with culturally diverse SPs focusing on underrepresented patient populations. Richards and Doorenbos (2016) described a three-week course abroad (India) for health care students and its preparation as well as the exchange focusing on global awareness and intercultural competency. Muir-Cochrane et al. (2018) developed four virtual resources focusing on mental health that unfolded during the student's programs, but no specific information was provided about the duration of the journeys. Liang et al. (2019) developed an 18-week embedded course on cultural care in child and adolescent care. The study conducted by Noble et al. (2014) described the introduction to nursing course as a series of 14 classes with two academic hours per session. Wolfe Kohlbry (2016) focused on a service-learning program to evaluate students' development of cultural sensitivity, social justice, collaboration and problem solving, but no information could be located on the actual duration of this intervention (Table 5).

\subsection{Instruments used to evaluate cultural competence}

A total of six articles used the "Transcultural Self-Efficacy Tool 
Table 5

Theoretical background, teaching methods, duration of the education and main findings/conclusions of the review studies.

\begin{tabular}{|c|c|c|c|c|}
\hline $\begin{array}{l}\text { Author, year and } \\
\text { country }\end{array}$ & Theoretical background & Teaching methods & Duration of the education & Main findings/conclusions \\
\hline $\begin{array}{l}\text { Allen et al. (2013) } \\
\text { Australia }\end{array}$ & $\begin{array}{l}\text { Social constructivist model } \\
\text { of health } \\
\text { Theory of transcultural } \\
\text { nursing }\end{array}$ & $\begin{array}{l}\text { Class debate } \\
\text { Discussion } \\
\text { Case scenarios } \\
\text { Lecture } \\
\text { Tutorials } \\
\text { Practicum laboratories }\end{array}$ & $\begin{array}{l}72 \mathrm{~h} \text { in total of activities distributed } \\
\text { across an } 8 \text {-week program comprising } \\
\text { theatrical presentation teaching ( } 1 \mathrm{~h} \text { per } \\
\text { week), tutorials ( } 2 \mathrm{~h} \text { per week), and labs } \\
\text { ( } 1 \mathrm{~h} \text { per week). }\end{array}$ & $\begin{array}{l}\text { - Nursing students improved perceived } \\
\text { confidence and knowledge skills. } \\
\text { - Nursing education should include } \\
\text { intercultural nursing and anti-racism and } \\
\text { anti-discrimination. }\end{array}$ \\
\hline $\begin{array}{l}\text { Amerson (2010) } \\
\text { USA }\end{array}$ & $\begin{array}{l}\text { Jeffreys' Cultural } \\
\text { Competence and } \\
\text { Confidence (CCC) Model }\end{array}$ & $\begin{array}{l}\text { Service-learning projects with local } \\
\text { and international communities } \\
\text { (cultural immersion) }\end{array}$ & $\begin{array}{l}\text { Students were divided into seven clinical } \\
\text { sections (groups of } 6-11 \text { students) of } \\
\text { which one had a one-week placement in } \\
\text { Guatemala }\end{array}$ & $\begin{array}{l}\text { - All subscales of the TSET increased after } \\
\text { service learning. } \\
\text { - The international group scored lowest in } \\
\text { all scores on the pretest, yet scored } \\
\text { highest on the posttest. } \\
\text { - The importance of cultural awareness in } \\
\text { nursing education was emphasized. }\end{array}$ \\
\hline $\begin{array}{l}\text { Grossman et al. } \\
\text { (2012) } \\
\text { USA \& Norway }\end{array}$ & $\begin{array}{l}\text { Theoretical background } \\
\text { unclear }\end{array}$ & Simulations & $\begin{array}{l}\text { Two simulation scenarios per semester } \\
\text { followed by } 20 \text { min of debriefing } \\
\text { sessions }\end{array}$ & $\begin{array}{l}\text { - Data showed significant differences, but } \\
\text { not on the "Practical" subscale. } \\
\text { - No statistically significant differences } \\
\text { were found in the two cohorts. } \\
\text { - There is a need for future studies } \\
\text { focusing on learning strategies related to } \\
\text { cultural awareness during simulation in } \\
\text { undergraduate and graduate programs. }\end{array}$ \\
\hline $\begin{array}{l}\text { Halter et al. } \\
\text { (2015) } \\
\text { USA }\end{array}$ & Jeffreys' CCC model & $\begin{array}{l}\text { Various teaching learning } \\
\text { interventions and strategies (e.g., } \\
\text { lecture, lecture with audience } \\
\text { participation, written paper, } \\
\text { reading literature from cultural } \\
\text { journals) }\end{array}$ & $\begin{array}{l}\text { Various durations for different teaching } \\
\text { learning interventions and strategies per } \\
\text { academic semester. (duration is not } \\
\text { specified) }\end{array}$ & $\begin{array}{l}\text { - No significant relationships between TSE } \\
\text { and the demographics examined were } \\
\text { found. } \\
\text { - Significant findings were found by } \\
\text { academic level and prior health care } \\
\text { experience. } \\
\text { - Students' perceptions of TSE can be } \\
\text { modified when using pertinent } \\
\text { educational interventions. }\end{array}$ \\
\hline $\begin{array}{l}\text { Jeffreys and } \\
\text { Dogan (2012) } \\
\text { USA }\end{array}$ & Jeffreys' CCC model & Teaching methods unclear & $\begin{array}{l}\text { Nursing curriculum course, } 30 \text { weeks of } \\
\text { medical and surgical courses, and four } \\
\text { 7.5-week courses, including clinical } \\
\text { rotations elapsed in between measures }\end{array}$ & $\begin{array}{l}\text { - Higher scores were found in senior } \\
\text { studets, except for the cognitive } \\
\text { subscale. } \\
\text { - All nurse educators should take } \\
\text { appropriate steps to ensure the } \\
\text { dissemination of quality cultural nursing } \\
\text { education. }\end{array}$ \\
\hline $\begin{array}{l}\text { Liang et al. } \\
\text { (2019) } \\
\text { Taiwan }\end{array}$ & $\begin{array}{l}\text { Sunrise Model (Leininger } \\
\text { and McFarland) and } \\
\text { Campinha-Bacote's process } \\
\text { of cultural competence }\end{array}$ & $\begin{array}{l}\text { Didactic teaching, the Sunrise } \\
\text { Model, interactive learning (role } \\
\text { play, presenting scenarios) and } \\
\text { reflective feedback }\end{array}$ & $\begin{array}{l}\text { Developed an } 18 \text {-week embedded course } \\
\text { on cultural care in child and adolescent } \\
\text { care }\end{array}$ & $\begin{array}{l}\text { - Students showed more positive } \\
\text { perceptions of their CCC after } \\
\text { completion of the ECC-CAC course. } \\
\text { - Two main themes were identified: } \\
\text { appreciation of the variety of learning } \\
\text { activities and the stimulating nature of } \\
\text { such an intervention. } \\
\text { - Students valued the chance to obtain } \\
\text { new cultural knowledge and share } \\
\text { personal cultural experiences. } \\
\text { Embedding cultural competence } \\
\text { education in nursing courses is essential } \\
\text { to improving nursing students' } \\
\text { perceptions of their cultural care } \\
\text { competency. }\end{array}$ \\
\hline $\begin{array}{l}\text { Muir-Cochrane } \\
\text { et al. (2018) } \\
\text { Australia }\end{array}$ & $\begin{array}{l}\text { Interpretive pedagogy } \\
\text { theory } \\
\text { Theory of planned behavior } \\
\text { (not accurately specified) }\end{array}$ & $\begin{array}{l}\text { Storytelling, case study-based } \\
\text { learning, and interpretive pedagogy }\end{array}$ & (duration is not specified) & $\begin{array}{l}\text { - Significant changes from pre- to posttests } \\
\text { were observed in the domains of } \\
\text { empathy, confidence, attitudes and } \\
\text { intention (cultural competence). }\end{array}$ \\
\hline $\begin{array}{l}\text { Noble et al. } \\
\text { (2014) } \\
\text { Israel }\end{array}$ & $\begin{array}{l}\text { Campinha-Bacote's Model } \\
\text { of Cultural Competence }\end{array}$ & $\begin{array}{l}\text { The introduction to nursing course: } \\
\text { lectures, classroom discussion, } \\
\text { student group presentations }\end{array}$ & $\begin{array}{l}\text { A series of } 14 \text { classes of two academic } \\
\text { hours per session }\end{array}$ & $\begin{array}{l}\text { - Integrative learning strategies applied to } \\
\text { students revealed significant increases in } \\
\text { cultural competence scores. } \\
\text { - Cultural competence teaching strategies } \\
\text { were recommended to be disseminated } \\
\text { in nursing education workshops, } \\
\text { seminars, and conferences. } \\
\text { - Future studies should explore the use of } \\
\text { measurement tools developed for } \\
\text { students and the theoretical and clinical } \\
\text { application of cultural competence. }\end{array}$ \\
\hline $\begin{array}{l}\text { Ozkara San } \\
\text { (2018) } \\
\text { USA }\end{array}$ & $\begin{array}{l}\text { Jeffrey's } \\
\text { CCC model }\end{array}$ & $\begin{array}{l}\text { Clinical simulation (implemented } \\
\text { for cultural competence education) } \\
\text { Standardized patient simulation }\end{array}$ & $\begin{array}{l}\text { The simulation scenarios were } \\
\text { embedded in a 15-week nursing course } \\
\text { with culturally diverse SPs focusing on } \\
\text { underrepresented patient populations }\end{array}$ & $\begin{array}{l}\text { - SET scores showed the largest changes in } \\
\text { the cognitive dimension of learning, } \\
\text { whereas the least affected dimension was } \\
\text { the affective one. }\end{array}$ \\
\hline
\end{tabular}




\begin{tabular}{|c|c|c|c|c|}
\hline $\begin{array}{l}\text { Author, year and } \\
\text { country }\end{array}$ & Theoretical background & Teaching methods & Duration of the education & Main findings/conclusions \\
\hline $\begin{array}{l}\text { Richards and } \\
\text { Doorenbos } \\
\text { (2016) } \\
\text { USA }\end{array}$ & $\begin{array}{l}\text { Benett's developmental } \\
\text { model of intercultural } \\
\text { sensitivity (DMIS) } \\
\text { Deardorffs process model of } \\
\text { intercultural competence } \\
\text { (PMIC) } \\
\text { Campinha-Bacote's model, } \\
\text { The Process of Cultural } \\
\text { Competence in the Delivery } \\
\text { of Healthcare Services }\end{array}$ & $\begin{array}{l}\text { Course on cultural experiences in } \\
\text { the cities and clinical practices at } \\
\text { hospital. * }\end{array}$ & $\begin{array}{l}\text { Service-learning program (duration is } \\
\text { not specified) }\end{array}$ & $\begin{array}{l}\text { - Specific intercorrelations between TSET } \\
\text { subscales were identified, but they could } \\
\text { not be used as predictors. } \\
\text { - DSPS strategy offers a valuable guide for } \\
\text { educators at all levels to foster cultural } \\
\text { competence development. } \\
\text { - No statistically significant improvement } \\
\text { for the ISS or IES scales were observed. } \\
\text { - Students developed special awareness of } \\
\text { their own cultural worldview, } \\
\text { particularly an openness to their host } \\
\text { country, as well as the use of skills to } \\
\text { advance their intercultural competence. } \\
\text { - Pre and posttests revealed statistically } \\
\text { significant differences in times for two } \\
\text { (knowledge and skill domains) out of the } \\
\text { five constructs of cultural competence } \\
\text { explored. } \\
\text { - Important differences in the type of } \\
\text { journey that students had completed for } \\
\text { this assignment, with variations from } \\
\text { one day to three weeks, and there was } \\
\text { great variability in the countries visited. }\end{array}$ \\
\hline
\end{tabular}

(TSET)" to evaluate changes regarding cultural competence after their interventions (Amerson, 2010; Grossman et al., 2012; Halter et al., 2015; Jeffreys and Dogan, 2012; Ozkara San, 2018; Allen et al., 2013). In addition, Allen et al. (2013) employed the "Quick Discrimination Index (QDI)". The rest of the studies combined different instruments to evaluate change. Richards and Doorenbos (2016) focused on intercultural aspects, evaluating "effectiveness" using the "Intercultural Effectiveness Scale" and the "sensitivity" of their mixed-methods program with the help of the "Intercultural Sensitivity Scale". Noble et al. (2014) followed a consistent design approach and used "Campinha-Bacote's Inventory for Assessing the Process of Cultural Competence" to measure cultural knowledge, cultural skill, cultural desire and cultural encounters.

Wolfe Kohlbry (2016) used two questionnaires to evaluate cultural competence variation: "The Inventory of Assessing the Process of Cultural Competence among Healthcare Professionals" (in its student version) and "The Cultural Self-Efficacy Scale".

Finally, two studies used a combination of assessment tools and focus groups (FGs) to evaluate the perceived changes in this domain. Muir-Cochrane et al. (2018) used the "Kiersma-Chen Empathy Scale (REF)", the "Mental Health Nursing Clinical Confidence Scale", and "The Cultural Competence Questionnaire (theory of planned behavior-(TPB)CCQ)" combined with FGs and interviews $(\mathrm{n}=21)$. Liang et al. (2019) also combined focus group interviews $(n=10)$ with a questionnaire, the "Self-perceived Cultural Care Competence" (SP-CCC) instrument (Table 3).

\subsection{Effects of cultural competence interventions on students' programs}

Allen et al. (2013) combined theoretical and practical learning environments using different methods and audio-visual material to prompt discussion and debate. The lecturers hoped this approach would promote students' self-reflection regarding culturally and socially determined values and biases and in a more global context (Tables 4 and 5). With a predominantly female sample, statistical data on dependent variables and pre- and post-measures suggested significant differences. According to Allen et al. (2013), this confirmed that students had improved perceived confidence or self-efficacy and knowledge skills.

Amerson's (2010) study used a convenience sample of students participating in a community health nursing course after having completed a service-learning project within communities. Amerson (2010) reported significant increases for each subscale of the TSET. It was noted that the international group scored lowest in all scores on the pretest, yet scored highest on the posttest.

Grossman et al. (2012) showed statistically significant differences pre and posttest for each subscale as well as the total of all subscales (Table 5). Similarly, Norwegian data showed significant differences, but not on the "Practical" subscale. Despite some discrepancies in resulting (practical and total) scores, no statistically significant differences could be found in the two cohorts.

Also using the TSET, Jeffreys and Dogan (2012) employed a purposive cross-sectional sample of novice and fourth-semester nursing students in an American university. Data analysis showed that means were higher for the senior semesters, except for the Cognitive subscale. For Jeffreys and Dogan (2012), all students, independent of their year, benefited from formal education on cultural competence (Tables 3 and 5).

Halter et al. (2015) used the TSET and reported significant changes for overall self-efficacy as well as the cognitive, practical and affective subscales (as previously reported by the three previous studies). The authors did not find significant relationships between TSE and the demographics examined. They suggested that students' perceptions of TSE can be modified when using pertinent educational interventions (Table 5).

The final study using the TSET to evaluate changes in self-efficacy perceptions was conducted by Ozkara San (2018). In general, the learning objectives of the Diverse Standardized Patient Simulation (DSPS) strategy were achieved, and they demonstrated positive changes in the cognitive, practical and affective learning domains. In this case, SET scores showed the largest changes in the cognitive dimension of learning, whereas the least affected dimension was the affective one. Ozkara San (2018) also reported specific intercorrelations between TSET subscales, but they could not be used as predictors. The author emphasized that the DSPS strategy offers a valuable guide for educators at all levels to foster cultural competence development.

Richards and Doorenbos (2016) carefully designed program curricula comprising structured reflection journals, group sessions and relational abilities as well as specific sessions in consonance with the "Association of American Colleges \& Universities (AACU)'s Intercultural Knowledge and Competence". The VALUE Rubric (2015) focuses on intercultural knowledge and skills development (Association of American Colleges \& Universities, 2015) This mixed-methods study did not report statistically significant improvement for the ISS or IES scales used in the study (Table 3). The qualitative analysis of the students' work 
provided evidence of students' developing special awareness of their own cultural worldview, particularly an openness to their host country, as well as the use of skills to advance their intercultural competence (Table 4).

Muir-Cochrane et al.'s (2018) mixed-methods study used several evaluation tools: "The Kiersma-Chen Empathy Scale Mental Health Nursing Clinical Confidence Scale", "The Cultural Competence Questionnaire (theory of planned behavior-(TPB)-CCQ)" as well as FGs and interviews. The authors indicated significant changes from pre- to posttests in the domains of empathy, confidence, attitudes and intention (cultural competence) (Table 4). The qualitative data from the FG interviews provided by the authors' emerging themes suggested specific changes from the starting point upon completion of the program. Students emphasized the quality and value of the materials and described changes in their empathy and attitudes towards culturally and linguistically different patients, with specific changes focusing on their cultural competence attitudes and empathy.

Liang et al. (2019) combined the "Self-Perceived Cultural Care Competence (SP-CCC) Questionnaire" in nursing students with FG interviews. Statistical analysis of the pre- and posttest revealed a significant improvement in most scores (Table 4). Liang et al. (2019) concluded that students showed more positive perceptions of their CCC after completion of the ECC-CAC course. Thematic content analysis of the FGs suggested two main themes: appreciation of the variety of learning activities proposed in the course and the stimulating nature of such an intervention. Students valued the chance to obtain new cultural knowledge and share personal cultural experiences.

The quasi-experimental study by Noble et al. (2014) evaluated the effectiveness of an educational intervention to increase first-year students' general cultural competence in two different schools of the same university (Table 3). Undergraduates who participated in the educational intervention course showed significantly increased scores compared to those students who were part of the control group, in which no significant increase could be identified (Table 5).

The article by Wolfe Kohlbry (2016) focused on the impact of an international immersion service-learning project on BSc nursing students' cultural competence. Pre and posttests revealed statistically significant differences in times for two (knowledge and skill domains) out of the five constructs of cultural competence explored. In measuring preand posttest means, both tools underlined growth in overall means for all constructs of cultural competence and cultural self-efficacy. Significant pre- and posttest means on the IAPCC-SV survey were demonstrated on the constructs of cultural knowledge and skill. Wolfe Kohlbry (2016) reported important differences in the type of journey that students had completed for this assignment, with variations from one day to three weeks, and there was great variability in the countries visited (including Latin American, Asian, and African destinations). Emerging themes from qualitative analyses were consistent with the statistical analyses of quantitative data, particularly for the cultural competency constructs identified in Campinha-Bacote's model (Tables 3 and 4).

When measuring tools before and after the trip, both surveys showed an increase in overall tools in all cultural competence and cultural selfefficacy structures (Table 4).

\section{Discussion}

The purpose of this systematic review was to examine and analyze studies assessing transcultural nursing education, primarily in bachelor's degree nursing study programs. It was found that interventions leading to the acquisition of cultural competences were integrated either in compulsory or in elective subjects according to these articles. The integration of nursing cultural care education in the category of elective subjects was insufficient. If the graduates did not select the subject during their studies, they would have a reduced opportunity to practice the knowledge and skills needed to provide culturally competent care.

A key difference was also identified regarding the duration and scope of the programs that focus on the acquisition of cultural competences. The results showed that a longer duration of the program provides more time for the integration of different teaching methods. The methods most frequently used in the examined studies include model situations, role playing or specific scenarios with reflective feedback (Liang et al., 2019; Allen et al., 2013; Ozkara San, 2018). A combination of the former allows for the training, development, and verification of cultural competences in practical care for children and adults. Richards and Doorenbos (2016) highlighted the contribution of a three-week course abroad for health care students. Such courses help to increase the awareness of cultural competences in clinical practice. Similarly, a contribution to increasing cultural competences through contact with people in international communities is described by Amerson (2010) and Wolfe Kohlbry (2016). We know that practice abroad is a challenge for students, but they will have wider knowledge and experience in real life in different cultural environments.

In our review, most authors used standardized tools for the evaluation of the effects of their educational interventions (Allen et al., 2013; Amerson, 2010; Grossman et al., 2012; Halter et al., 2015). In all cases, the students were tested before the start and after the end of the program. It can be noted that the studies using the TSET found changes in the individual items; however, the level of the achieved changes was different. The reason might involve the use of different teaching methods, different contents and different scopes of the educational interventions or may be linked to the individual characteristics of the students. That may also be why the tools were usually complemented by another standardized tool in a number of studies.

The authors of five studies made use of different standardized tools aimed at evaluating the attitudes, empathy, knowledge, skills and cultural desire (Liang et al., 2019; Muir-Cochrane et al., 2018; Wolfe Kohlbry, 2016; Noble et al., 2014; Richards and Doorenbos, 2016). The use of the previously mentioned tools enabled a more objective assessment of the changes achieved, which led to increased cultural competences in the students. Although the statistical analyses did not show any significant improvement in some cases, the qualitative analyses of the students' work demonstrated a change in their awareness of their own cultural worldview. Liang et al. (2019) stated that after passing the course, the students showed a significant improvement in most of the areas under observation, primarily knowledge, attitudes and skills. A similar result was obtained in the study by Noble et al. (2014). The study by Wolfe Kohlbry (2016) evaluating the effect of a sojourn in another country demonstrated a significant shift in individual constructs of cultural competence.

\subsection{Study limitations}

This review has some limitations. Only articles published in English were ultimately included. After careful examination of the selected articles for this review, the bias assessment was not applicable, as none of the selected studies used an experimental design. Most studies were mainly pre-post experiments or only post-test experiments with convenience samples, without using a control group, blinding or randomization. Indeed, the results of this review are based on the details reported in the studies included in this study. The training content, duration of the training, the characteristics of the participants, and some other details were not clear in the methods of some studies.

\section{Conclusion}

The papers examined underline the notion that it is key for nurses to be familiar with the different cultural habits and ways to care for patients in such circumstances. Limited studies have generally proven the effectiveness of transcultural nursing education provided to nursing students. Although the education content, training methods and training periods were not standardized, researchers generally evaluated the education program using the same or similar measurement tools. We 
believe that transcultural nursing education programs should be standardized in terms of content, duration and basic teaching methods for nursing students from all cultures. More comprehensive, valid and reliable measurement tools should be developed to evaluate those programs. In addition, nursing students' cultural competencies should be explored by observational and/or experimental studies to evaluate nursing education regarding cultural care. To conclude, we believe that all nursing students should be given the opportunity to develop greater awareness of other cultures and ways to care for them. We consider that aspects such as communication, language, religion, social values and cultural norms should be further explored in the nursing curriculum to facilitate caring for patients and families of diverse origins.

\section{Funding}

This review was funded by the Erasmus + Program of the European Union, Turkish National Agency (Project no: 2019-1-TR01-KA203076879 "Better \& Effective Nursing Education For Improving Transcultural nursing Skills (BENEFITS)". "However, the European Commission and Turkish National Agency cannot be held responsible for any use which may be made of the information contained herein."

\section{CRediT authorship contribution statement}

Betuil Tosun: Conceptualization, Methodology, Data curation, Writing - original draft preparation, Visualization, Investigation, Supervision, Writing - review \& editing. Ayla Yava: Conceptualization, Methodology, Writing - original draft preparation, Visualization, Investigation, Supervision. Ezgi Dirgar: Conceptualization, Methodology, data curation, Writing - original draft preparation. Eda Başustaoğlu Şahin: Conceptualization, Methodology, Data curation, Writing - original draft preparation, Visualization, Investigation. Emel Bahadir Yılmaz: Conceptualization, Methodology, Data curation, Writing - original draft preparation, Software, Writing - original draft, Visualization, Investigation. Katalin Papp: Conceptualization, Methodology, Data curation, Writing - original draft preparation, Visualization, Investigation, Supervision. Valérie Tóthova: Conceptualization, Methodology, Software, Data curation, Writing - original draft preparation, Visualization, Investigation, Supervision. Věra Hellerova: Conceptualization, Methodology, Data curation, Writing - original draft preparation, Visualization, Investigation. Mirko Prosen: Conceptualization, Methodology, Writing - original draft preparation, Supervision, Writing - review \& editing. Sabina Licen: Conceptualization, Methodology, Writing - original draft preparation, Supervision, Writing - review \& editing. Igor Karnjus: Conceptualization, Methodology, Writing original draft preparation. M. Dolors Bernabeu Tamayo: Conceptualization, Methodology, Writing - original draft preparation, Supervision, Writing - review \& editing. Juan Manuel Leyva-Moral: Conceptualization, Methodology, Writing - original draft preparation, Supervision, Writing - review \& editing. Ann Claeys: Conceptualization, Data curation, Methodology, Writing - original draft preparation. Sandra TricasSauras: Conceptualization, Methodology, Writing - original draft preparation, Supervision, Writing - review \& editing.

\section{Acknowledgements}

We thank Mehmet Ali Çıkımoğlu and Mehmet Emin Bindal from Gaziantep Provincial Health Directorate for their support to our project.

\section{References}

Albougami, A.S., Pounds, K.G., Alotaibi, J.S., 2016. Comparison of four cultural competence models in transcultural nursing: a discussion paper. Int. Arch. Nurs. Health Care 2 (4), 1-5. https://doi.org/10.23937/2469-5823/1510053.

Allen, J., Brown, L., Duff, C., Nesbitt, P., Hepner, A., 2013. Development and evaluation of a teaching and learning approach in cross-cultural care and antidiscrimination in university nursing students. Nurs. Educ. Today 33 (12), 1592-1598. https://doi.org/ 10.1016/j.nedt.2012.12.006.

Amerson, R., 2010. The impact of service-learning on cultural competence. Nurs. Educ. Perspect. 31 (1), 18-22.

Association of American Colleges \& Universities, 2015. Intercultural Knowledge and Competence VALUE Rubric. Association of American Colleges \& Universities, Washington. 〈http://www.aacu.org/value/rubrics/intercultural-knowledge〉.

Brooks, L.A., Manias, E., Bloomer, M.J., 2019. Culturally sensitive communication in healthcare: a concept analysis. Collegian 26, 383-391. https://doi.org/10.1016/j. colegn.2018.09.007.

Byrne, D., 2020. Evaluating cultural competence in undergraduate nursing students using standardized patients. Teach. Learn. Nurs. 15, 57-60. https://doi.org/ 10.1016/j.teln.2019.08.010

Campinha-Bacote, J., 2011. Delivering patient-centered care in the midst of a cultural conflict: the role of cultural competence. Online J. Issues Nurs. 16, 5.

Centre for Reviews and Dissemination (CRD), 2009, Systematic reviews. CRD's Guidance for Undertaking Reviews in Health Care. 〈https://www.york.ac.uk/media/crd/Syst ematic_Reviews.pdf $\rangle$. (Accessed 10 April 2020).

Chen, H.C., Jensen, F., Measom, G., Bennett, S., Nichols, N.D., Wiggins, L., Anderton, A., 2018. Factors influencing the development of cultural competence in undergraduate nursing students. J. Nurs. Educ. 57 (1), 40-43. https://doi.org/10.3928/0148483420180102-08.

Choi, J.S., Kim, J.S., 2018. Effects of cultural education and cultural experiences on the cultural competence among undergraduate nursing students. Nurs. Educ. Prac. 29, 159-162. https://doi.org/10.1016/j.nepr.2018.01.007.

Cruz, J.P., Alquwez, N., Cruz, C.P., Felicilda-Reynaldo, R.F.D., Vitorino, L.M., Islam, S.M. S., 2017. Cultural competence among nursing students in Saudi Arabia: a crosssectional study. Int. Nurs. Rev. 64 (2), 215-223. https://doi.org/10.1111/inr.12370.

Cruz, J.P., Estacio, J.C., Bagtang, C.E., Colet, P.C., 2016. Predictors of cultural competence among nursing students in the Philippines: a cross-sectional study. Nurs. Educ. Today 46, 121-126. https://doi.org/10.1016/j.nedt.2016.09.001.

Grossman, S., Mager, D., Opheim, H.M., Torbjornsen, A., 2012. A binational simulation study to improve cultural awareness in nursing students. Clin. Simul. Nurs. 8 (8), 341-346. https://doi.org/10.1016/j.ecns.2011.01.004.

Halabi, J.O., de Beer, J., 2018. Exploring the cultural competence of undergraduate nursing students in Saudi Arabia. Nurs. Educ. Today 62, 9-15. https://doi.org/ 10.1016/j.nedt.2017.12.005.

Halter, M., Grund, F., Fridline, M., See, S., Young, L., Reece, C., 2015. Transcultural selfefficacy perceptions of baccalaureate nursing students. J. Transcult. Nurs. 26 (3), 327-335. https://doi.org/10.1177/1043659614526253.

Hultsjö, S., Bachrach-Lindström, M., Safipour, J., Hadziabdic, E., 2019. "Cultural awareness requires more than theoretical education" - nursing students' experiences. Nurs. Educ. Prac. 39, 73-79. https://doi.org/10.1016/j.nepr.2019.07.009.

Jeffreys, M.R., Dogan, E., 2012. Evaluating the influence of cultural competence education on students' transcultural self-efficacy perceptions. J. Transcult. Nurs. 23 (2), 188-197. https://doi.org/10.1177/1043659611423836.

Kaihlanen, A.M., Hietapakka, L., Heponiemi, T., 2019. Increasing cultural awareness: qualitative study of nurses' perceptions about cultural competence training. BMC Nurs. 18, 1-9. https://doi.org/10.1186/s12912-019-0363-x.

Karatay, G., Bowers, B., Karadağ, E.B., Demir, M.C., 2016. Cultural perceptions and clinical experiences of nursing students in Eastern Turkey. Int. Nurs. Rev. 63, 547-554.

Ke, Y.T., Hsu, M.T., 2015. An exploration of nursing preceptorship and functions and nurses' intention to stay from the perspective of cultural differences. Nurs. Educ. Today 35, 597-601. https://doi.org/10.1016/j.nedt.2014.12.019.

Liang, H.F., Wu, K.M., Hung, C.C., Wang, Y.H., Chen, Y.C., 2019. Evaluation of nursing students' perceptions of their cultural care competency: a mixed method study in Taiwan. Nurse Educ. Pract. 41, 102639 https://doi.org/10.1016/j. nepr.2019.102639.

McFarland, M.R., Wehbe-Alamah, H.B., 2019. Leininger's theory of culture care diversity and universality: an overview with a historical retrospective and a view toward the future. J. Transcult. Nurs. 30 (6), 540-557. https://doi.org/10.1177/ 1043659619867134.

Moher, D., Liberati, A., Tetzlaff, J., Altman, D.G., Group, T.P., 2009. Reprint-preferred reporting items for systematic reviews and meta-analyses: the PRISMA statement. Phys. Ther. 6, 1-6. https://doi.org/10.1371/journal.pmed.1000097.

Muir-Cochrane, E., O'Kane, D., McAllister, M., Levett-Jones, T., Gerace, A., 2018. Reshaping curricula: culture and mental health in undergraduate health degrees. Int J. Ment. Health Nurs. 27 (2), 652-661. https://doi.org/10.1111/inm.12350.

Noble, A., Nuszen, E., Rom, M., Noble, L.M., 2014. The effect of a cultural competence educational intervention for first-year nursing students in Israel. J. Transcult. Nurs. 25 (1), 87-94. https://doi.org/10.1177/1043659613503881.

O’Brien, E.M., O’Donnell, C., Murphy, J., O’Brien, B., Markey, K., 2021. Intercultural readiness of nursing students: an integrative review of evidence examining cultural competence educational interventions. Nurse Educ. Pract. 50 (1), 102966 https:// doi.org/10.1016/j.nepr.2021.102966.

Ozkara San, E.O., 2018. Effect of the diverse standardized patient simulation (DSPS) cultural competence education strategy on nursing students' transcultural selfefficacy perceptions. J. Transcult. Nurs. 30 (3), 291-302. https://doi.org/10.1177/ 1043659618817599.

Papadopoulos, I., Lazzarino, R., Koulouglioti, C., Aagard, M., Akman, Ö., Alpers, L.M., Zorba, A., 2021. The importance of being a compassionate leader: the views of nursing and midwifery managers from around the world. J. Transcult. Nurs. 1-13. https://doi.org/10.1177/10436596211008214.

Popay, J., Roberts, H., Sowden, A., Petticrew, M., Arai, L., Rodgers, M., Britten, N., Roen, K., Duffy, S., 2006. Guidance on the Conduct of Narrative Synthesis in 
Systematic Reviews: a Product of the ESRC Methods Programme (Version I) University of Lancaster, Lancaster, UK. https://doi.org/10.13140/2.1.1018.4643.

Porritt, K., Gomersall, J., Lockwood, C., 2014. JBI's systematic reviews: study selection and critical appraisal. AJN Am. J. Nurs. 114 (6), 47-52. https://doi.org/10.1097/01. NAJ.0000450430.97383.64.

Prosen, M., 2015. Introducing transcultural nursing education: implementation of transcultural nursing in the postgraduate nursing curriculum. Procedia Soc. Behav. Sci. 174, 149-155. https://doi.org/10.1016/j.sbspro.2015.01.640.

Quickfall, J., 2014. Cultural competence in practice: the example of the community nursing care of asylum applicants in Scotland. Divers Equal Health Care 11, 247-253.

Raigal-Aran, L., Rifà-Ros, R., Borruel-Llovera, A., Ferré-Grau, C., 2017. Systematic review on cultural competence research on health professionals in Spain. Rev. ROI Enferm. 40 (11-12), 780-787.

Repo, H., Vahlberg, T., Salminen, L., Papadopoulos, I., Leino-Kilpi, H., 2017. The cultural competence of graduating nursing students. J. Transcult. Nurs. 28 (1), 98-107. https://doi.org/10.1177/1043659616632046.
Richards, C.A., Doorenbos, A.Z., 2016. Intercultural competency development of health professions students during study abroad in India. J. Nurs. Educ. Pract. 6 (12), 89-98. https://doi.org/10.5430/jnep.v6n12p89.

Sarafis, P.A., Malliarou, M.M., 2013. Cultural self-efficacy of baccalaureate nursing students in a Greek University. Iran. J. Nurs. Midwifery Res. 18 (6), 446-450.

Tufanaru, C., Munn, Z., Aromataris, E., Campbell, J., Hopp, L., 2017. Chapter 3: Systematic reviews of effectiveness. In: Aromataris, E., Munn, Z. (Eds.), JBI Manual for Evidence Synthesis, JBI, 2020. 〈https://doi.org/10.46658/JBIMES-20-04〉. (Accessed 10 April 2020).

Vassar, M., Atakpo, P., Kash, M.J., 2016. Manual search approaches used by systematic reviewers in dermatology. J. Med. Libr. Assoc.: JMLA 104 (4), 302-304. https://doi. org/10.3163/1536-5050.104.4.009.

Von Ah, D., Cassara, N., 2013. Perceptions of cultural competency of undergraduate nursing students. Open Nurs. J. 3, 182-185. https://doi.org/10.4236/ ojn.2013.32024.

Wolfe Kohlbry, P., 2016. The Impact of international service-learning on nursing students' cultural competency. J. Nurs. Scholarsh. 48 (3), 303-311. https://doi.org/ 10.1111/jnu.12209. 